\title{
Application of TAPM to predict photochemical air pollution over Portugal
}

\author{
C. Ribeiro ${ }^{1}$, C. Borrego ${ }^{1,2} \&$ M. Coutinho ${ }^{1}$ \\ ${ }^{1} I D A D$ - Institute of Environment and Development, Aveiro, Portugal \\ ${ }^{2}$ Department of Environment and Planning, University of Aveiro, \\ Portugal
}

\begin{abstract}
The main objective of this paper is to study photochemical air pollution in Portugal through the application of the "The Air Pollution Model" (TAPM) (version 2.0), a 3D prognostic model that solves the fundamental fluid dynamics and scalar transport equations to predict both meteorology and air pollution concentrations. The possibility of using a meso-meteorological and dispersion model on an hourly base during an entire year represents an important achievement for air quality studies. The model was applied to Portugal, for the year 2003, to predict ozone concentrations. The simulation domain was $350 \mathrm{x}$ $700 \mathrm{~km}$ with nested horizontal resolutions of 30 and $10 \mathrm{~km}$. This domain included the entire Portuguese mainland and some of the surrounding ocean in order to adequately simulate the complexity of the atmospheric flow. Model predictions of meteorological surface parameters, such as wind and temperature, were compared with measurements of six meteorological monitoring sites. The Index of Agreement (IOA) was applied between observations and model results predicted on one year-long meteorological parameters. IOA is greater than 0.50 for all parameters, indicating a good agreement with measurements. Predicted ozone concentrations were compared with measurements from twelve air monitoring sites using the Paired Peak Estimation and the Median Bias Error. This numerical tool demonstrates a satisfactory performance to calculate mesoscale circulation patterns and photochemical air pollution over Portugal, providing important information to be used by decision-makers for air quality assessment.
\end{abstract}

Keywords: photochemical air pollution, mesoscale simulation, ozone. 


\section{Introduction}

Mesoscale circulations are phenomena sufficiently important for the photochemical simulation and its representation generally is made through mesometeorological models capable to simulate the three-dimensional meteorological fields. Portugal is frequently under the influence of meso-meteorological circulations. The majority of the population and industry are located in the coastal area where sea breezes play an important role in the dispersion of atmospheric pollutants. In order to adequately study the circulation patterns of primary pollutants, as well as photochemical production it is necessary to simulate the atmospheric flow with mesocale models.

Most of air pollution dispersion models use semi-empirical or analytical approaches with input meteorological information typically derived from local surface-based observations. This meteorological information is not always available or has not sufficient detail, which can turn the application of these models very difficult. TAPM is an alternative 3D prognostic model that solves the fundamental fluid dynamics and scalar transport equations to predict meteorology and pollutant concentrations at local scale based on data obtained at global level. The approach followed by TAPM eliminates the need for specific meteorological data, while still offering the option of assimilating any observed meteorological data that might be available, and still simulates year-long periods with relative rapidity of calculation.

The possibility of using a meso-meteorological and dispersion model on an hourly base during an entire year represents an important achievement for air quality studies. The model was applied to Portugal, for the summer 2003, with the aim of predicting ozone concentrations.

\section{Model description}

TAPM is a three-dimensional prognostic model that solves the fundamental fluid dynamics and scalar transport equations to predict both meteorology and air pollution concentrations [1]. It uses global input databases of terrain height, land use, sea-surface temperature, and synoptic meteorological analyses. A complete description of TAPM version 2.0 and details of equations and parameterizations, including the numerical methods used to solve the model equations, can be found in [2] and [3], while a summary of some recent verification studies performed by CSIRO can be found in [4].

The meteorological component of TAPM predicts the local-scale flow, such as sea breezes and terrain induced circulations, given the larger scale synoptic meteorological fields. The model solves the momentum equations for horizontal wind components, the incompressible continuity equation for the vertical velocity in a terrain-following coordinate system, and scalar equations for potential virtual temperature, specific humidity of water vapour, cloud water and rain water. Pressure is determined from the sum of hydrostatic and optional nonhydrostatic components, and a Poisson equation is solved for the non-hydrostatic 
component. Explicit cloud micro-physical processes are included. Wind observations can optionally be assimilated into the momentum equations as nudging terms. The turbulence closure terms in these mean equations use a gradient diffusion approach, including a counter-gradient term for the heat flux, with eddy diffusivity determined using prognostic equations for turbulence kinetic energy and eddy dissipation rate. A weighted vegetative canopy, soil and urban land-use scheme is used at the surface, while radiative fluxes, both at the surface and at upper levels, are also included. Boundary conditions for the turbulent fluxes are determined by Monin-Obukhov surface-layer scaling variables and parameterisations for stomatal resistance.

The air pollution component of TAPM uses the predicted meteorology and turbulence from the meteorological component, and consists of an Eulerian gridbased set of prognostic equations for pollutant concentration and an optional Lagrangean particle mode that can be used on the inner-most nest for pollution for selected point sources to allow a more detailed account of near-source effects, including gradual plume rise.

The chemical mechanism is based on the semi-empirical mechanism called the Generic Reaction Set (GRS) of Azzi et al. [5], with the hydrogen peroxide modification of Venkatram et al. [6]. In chemistry mode, there are ten reactions for thirteen species: smog reactivity (Rsmog), the radical pool (RP), hydrogen peroxide $\left(\mathrm{H}_{2} \mathrm{O}_{2}\right)$, nitric oxide $(\mathrm{NO})$, nitrogen dioxide $\left(\mathrm{NO}_{2}\right)$, ozone $\left(\mathrm{O}_{3}\right)$, sulphur dioxide $\left(\mathrm{SO}_{2}\right)$, stable non-gaseous organic carbon (SNGOC), stable gaseous nitrogen products (SGN), stable non-gaseous nitrogen products (SNGN), stable non gaseous sulphur products (SNGS), plus Airborne Particulate Matter (APM) and Fine Particulate Matter (FPM) that include secondary particulate concentrations consisting of (SNGOC), (SNGN), and (SNGS) [1].

\section{Model application}

TAPM was applied to the Continental region of Portugal, with a horizontal domain of $350 \times 750 \mathrm{~km}$, as shown in Figure 1, with nested resolutions of 30, 10 $\mathrm{km}$ and a vertical grid of $8000 \mathrm{~m}$ and 25 levels, with the first level $10 \mathrm{~m}$ above the ground. The model was applied for a period of 2 months from $1^{\text {st }}$ of July 2003 to $31^{\text {st }}$ of August 2003.

The Portuguese national air quality network used for validation of the modelling results includes many types of sites such as background, traffic and industrial monitoring stations, according to the criteria developed by the European Environment Agency. During the period selected for simulation only 12 monitoring stations, mainly concentrated in the coastal area, showed a consistent and feasible data.

The validation of the meteorological component was made with field data obtained in six meteorological stations distributed over the domain area. This analysis was developed for temperature, wind velocity and wind direction measured at $10 \mathrm{~m}$ above ground.

Locations of meteorological and air quality stations are shown in Figure 1. 


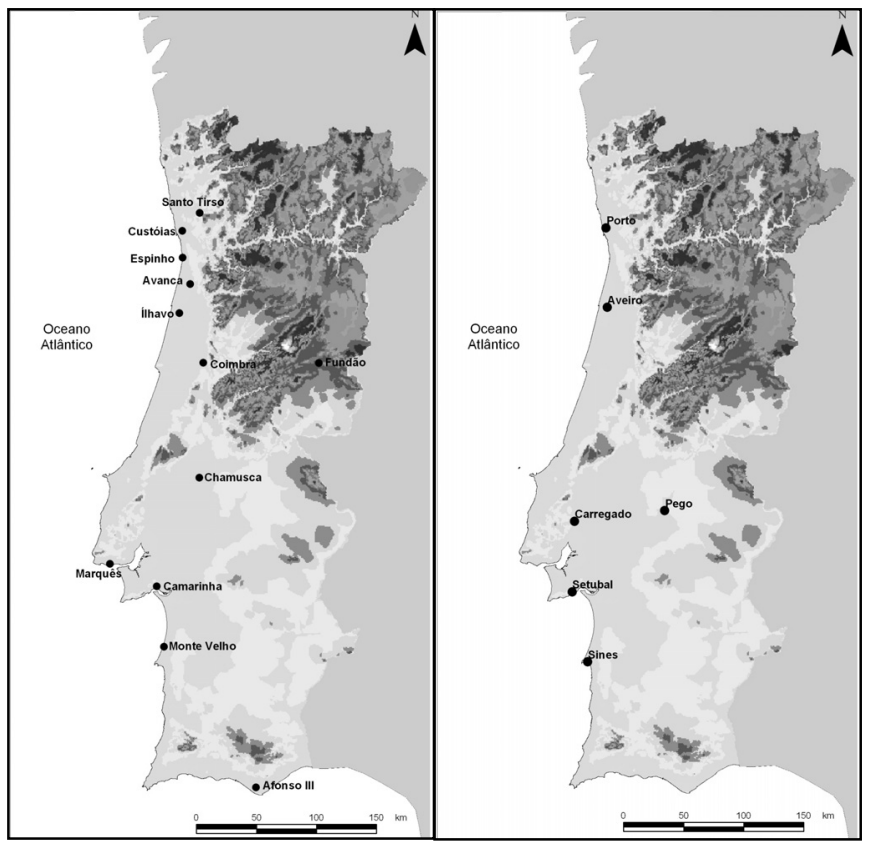

Figure 1: $\quad$ Simulated domain for Continental Portugal $(350 \times 750 \mathrm{~km})$ with the location of air quality (left) and meteorology (right) monitoring sites.

\subsection{Emissions}

The area source annual emission data for $\mathrm{NO}_{\mathrm{x}}, \mathrm{SO}_{2}, \mathrm{CO}$ and $\mathrm{NMVOC}$ were obtained from the Portuguese EMEP database [7] for the year 2001, for each pollutant activity (traffic, solvents, industrial and residential combustion and others).

These emissions were spatially disaggregated in order to obtain the resolution required, using adequate statistical indicators (types of fuel consumption and population census data) for each pollutant activity [8].

Annual emissions of large point sources were obtained directly from the available monitoring data of each industrial plant compiled on a database.

\subsection{Meteorological episode}

The meteorological episode was selected after the analysis of the ozone episodes measured in the national air quality network. Attention focused in the period between July and August 2003 that is considered as the most problematic in recent years for photochemical air pollution. In this 2003 there were 374 exceedances to the information threshold of ozone $\left(180 \mu \mathrm{g} \cdot \mathrm{m}^{-3}\right)$ between April and September with 256 exceedances only in August. 
This period coincides with a major heat wave across much of Europe in the first two weeks of August 2003, during which temperatures peaked in August $1^{\text {st }}$, specially in the southern region of the country, with new records for the maximum of $47,3^{\circ} \mathrm{C}$ in Amaraleja and for the minimum of $30,1^{\circ} \mathrm{C}$ in Portalegre [9].

The Portuguese National Observatory of Health reported [9] an excess of $43 \%$ of deaths in Portugal for the period from $30^{\text {th }}$ July to August $15^{\text {th }} 2003$ above the average for this time of year.

\section{Results and discussion}

\subsection{Surface meteorology}

Meteorological model predictions were extracted at the nearest grid point to each of the five meteorological monitoring sites on the $10 \mathrm{~km}$ grid spacing at $10 \mathrm{~m}$ above the ground for temperature and wind speed and direction. Statistics included the root mean square error (RMSE), the index of agreement (IOA) and the skill measurements $\left(\right.$ SKILL $_{E}$, SKILL $_{V}$, SKILL $\left._{R}\right)$ and are based on the recommendations of Willmott [10]. The IOA is a measure of how well predicted variations about the observed mean are represented, with a value greater than about 0.50 considered to be good and 1 perfect. If the model shows skill the statistics SKILL $L_{V}$ are near 1 and SKILL ${ }_{E}$ and SKILL ${ }_{R}$ must be less than 1. Table 1 includes the statistics of observations and model predictions for five meteorological monitoring sites.

Table 1: $\quad$ Statistics for the TAPM simulation for July to August 2003.

\begin{tabular}{|c|c|c|c|c|c|c|}
\hline & & Aveiro & Pego & Carregado & Setúbal & Sines \\
\hline \multirow{5}{*}{ Wind speed } & RMSE & 2.45 & 1.56 & 3.48 & 7.47 & 1.76 \\
\hline & IOA & 0.67 & 0.79 & 0.58 & 0.42 & 0.84 \\
\hline & SKILLE $_{\mathrm{E}}$ & 0.87 & 0.73 & 0.98 & 2.11 & 0.69 \\
\hline & SKILLV & 0.89 & 0.93 & 0.88 & 0.90 & 0.98 \\
\hline & SKILL $_{R}$ & 1.20 & 0.86 & 1.56 & 3.06 & 0.77 \\
\hline \multirow{5}{*}{$\begin{array}{l}\text { west-east } \\
\text { component } \\
\text { (u) }\end{array}$} & RMSE & 2.00 & 2.25 & 2.37 & 2.85 & 1.96 \\
\hline & IOA & 0.79 & 0.87 & 0.68 & 0.56 & 0.89 \\
\hline & SKILLE $_{E}$ & 0.88 & 0.51 & 1.02 & 1.57 & 0.62 \\
\hline & SKILLV & 1.14 & 0.85 & 1.15 & 1.71 & 1.06 \\
\hline & SKILL $_{R}$ & 0.93 & 0.65 & 1.13 & 1.62 & 0.66 \\
\hline \multirow{5}{*}{$\begin{array}{l}\text { south-north } \\
\text { component } \\
\text { (v) }\end{array}$} & RMSE & 2.06 & 2.32 & 2.70 & 3.68 & 1.95 \\
\hline & IOA & 0.84 & 0.78 & 0.78 & 0.64 & 0.93 \\
\hline & SKILL $_{\mathrm{E}}$ & 0.85 & 1.00 & 1.05 & 1.38 & 0.58 \\
\hline & SKILLV & 1.27 & 1.38 & 1.40 & 1.63 & 1.09 \\
\hline & SKILL $_{R}$ & 0.86 & 1.06 & 1.08 & 1.45 & 0.55 \\
\hline \multirow{5}{*}{ Temperature } & RMSE & 6.90 & 3.75 & 3.52 & 5.47 & 2.67 \\
\hline & IOA & 0.75 & 0.94 & 0.93 & 0.83 & 0.92 \\
\hline & SKILL $_{\mathrm{E}}$ & 1.52 & 0.48 & 0.45 & 0.69 & 0.45 \\
\hline & SKILLV & 1.18 & 0.99 & 0.91 & 0.85 & 0.93 \\
\hline & SKILL $_{R}$ & 1.43 & 0.51 & 0.52 & 0.84 & 0.54 \\
\hline
\end{tabular}

These parameters indicate a reasonable performance of the model for the index of agreement (IOA). The IOA is greater than 0.50 for all parameters indicating therefore that a good adjustment exists between the estimated and 
measured values. In the particular case of Setúbal, the lower values of IOA for wind speed can be justified by the insufficiency of data for this parameter on this particular meteorological station.

The comparison of the IOA determined for the meteorological parameters shows that in general, the IOA for the estimate of the temperature is better than the one obtained for the wind. This fact is expectable and confirms the good behavior of the radiative algorithm and land use parameterization of the model. The simulation of the atmospheric flow, analyzed through wind velocity and direction represents a phenomenon of bigger complexity resulting in a slightly lower value of IOA for these variables. The root mean square error values are lower than the standard deviations of the observations for most of the sites, indicating a high skill for the model. There are differences between the model and observed values of the wind components and speed, but these differences can be justified by insufficiency of data.

\subsection{Ozone ground level concentrations}

TAPM calculates ozone hourly average concentrations for the entire domain. Analysis of the modelling results was performed using time series, scatter plots and the calculation of the mean bias error (MBE) following a methodology used by EPA [11].

Figure 2 shows the spatial ozone concentration fields for July and August of 2003, in Portugal.

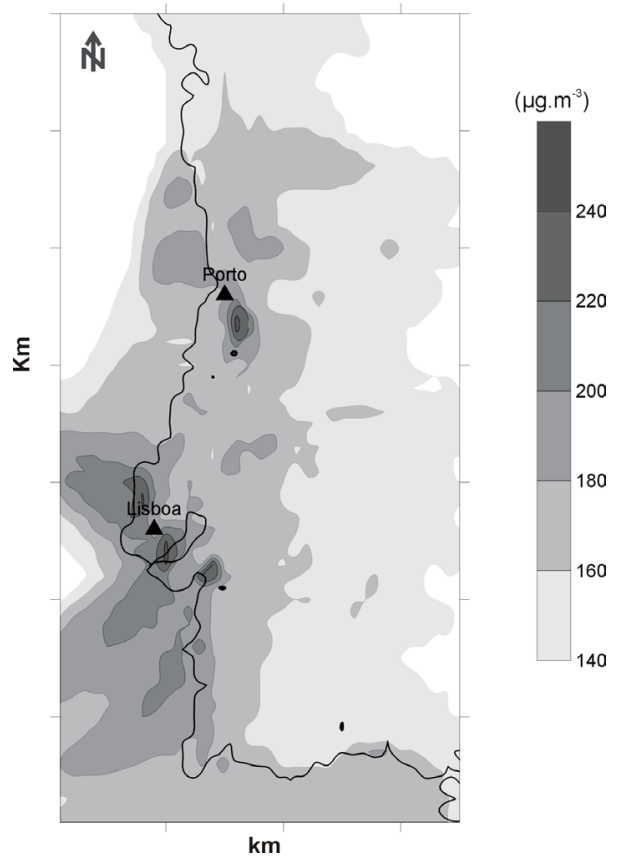

Figure 2: $\quad$ Maximum $\mathrm{O}_{3}$ concentration fields for July and August of 2003. 
According to modeling results, Ozone exceedances occurred during the simulated period, in large areas of Portugal where there were not any field data. Concentration patterns show that there is a potential advection and transport of the pollutants emitted from the major urban centers (Porto and Lisbon) to the coast and to some inland parts of Portugal. This scenario confirms other mesoscale meteorological simulations performed in this region by other authors [11-13].
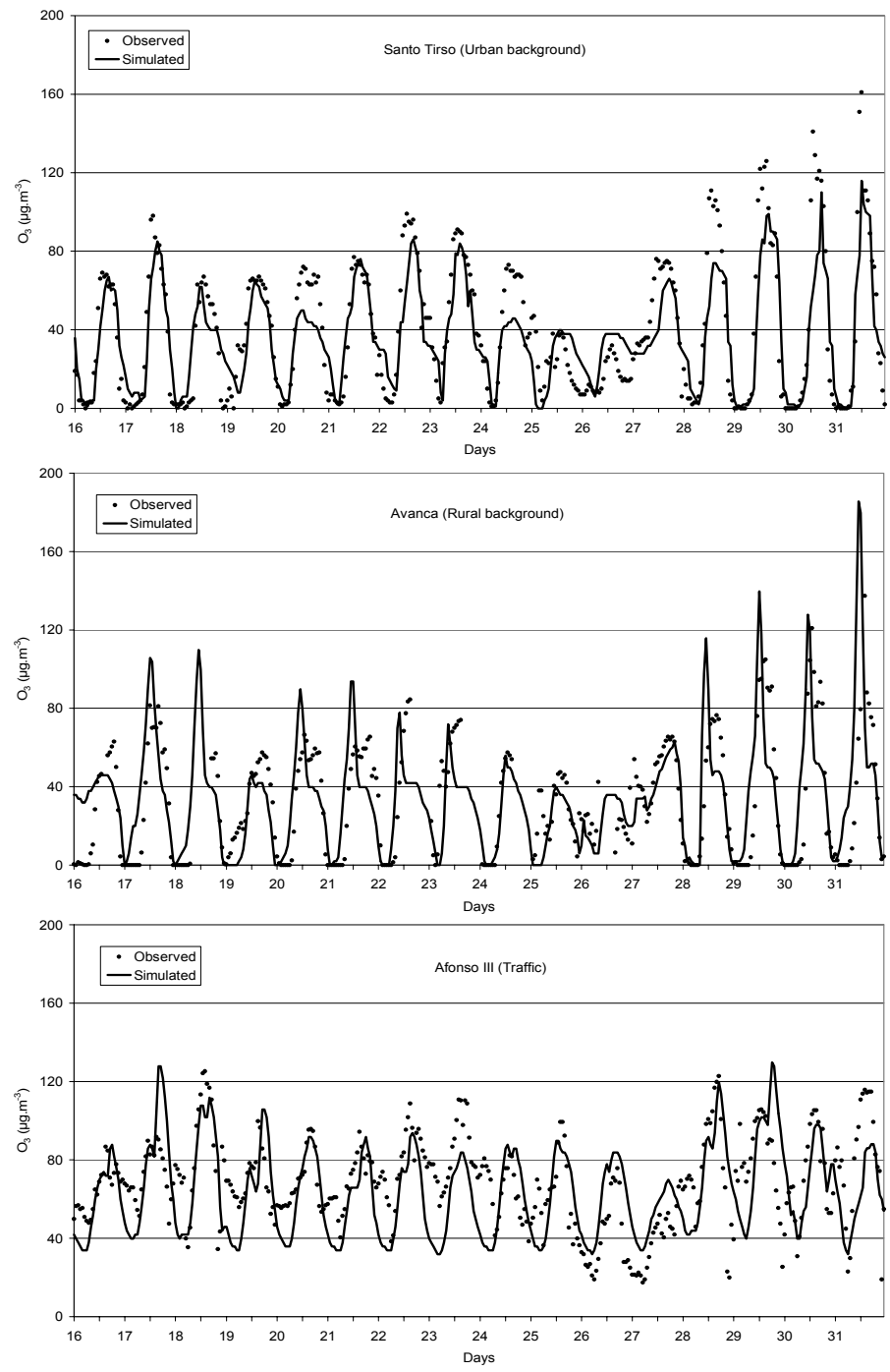

Figure 3: Observed and simulated hourly maximum ozone values for different types or air quality monitoring sites. 
Figure 3 shows time series plots for a selection of three "representative" air quality monitoring sites, chosen to cover the different type of monitoring stations. The model is able to simulate the hourly maximum ozone variability and reproduces the episodic events of high ozone maximums as well as the interdaily variability.

The evaluation of the performance of the model is shown in Table 2. These results suggest that in these particular simulations the model has a tendency to underestimate the estimated values, in comparison with the measured data, since in 11 of the 12 sites the value of MBE is negative.

Table 2: $\quad$ Mean bias Error (MBE) for ozone.

\begin{tabular}{cc}
\hline Air Quality Site & MBE \\
\hline Santo Tirso & -14 \\
\hline Custóias & -14 \\
\hline Espinho & -11 \\
\hline Avanca & 6 \\
\hline Ílhavo & -25 \\
\hline Coimbra & -26 \\
\hline Fundão & -1 \\
\hline Chamusca & -2 \\
\hline Quinta Marquês & -29 \\
\hline Camarinha & -10 \\
\hline Monte Velho & -18 \\
\hline Afonso III & -10
\end{tabular}

\section{Conclusions}

TAPM was used to predict photochemical air pollution in Portugal, in July and August 2003. Model results were compared with data from national air and meteorological monitoring network. Results show that TAPM has predicted extreme concentration statistics for smog ozone in some sites but, in general, is able to simulate the hourly maximum ozone variability and reproduces the episodic events. The spatial ozone concentration shows that the pollutants emitted from Porto and Lisbon affects the coast and some inland parts of Portugal.

\section{References}

[1] Hurley, P., The Air Pollution Model (TAPM) Version 2. Part 1: technical description, CSIRO Atmospheric Research Technical Paper No. 55, 2002.

[2] Hurley, P., An evaluation of several turbulence schemes for the prediction of mean and turbulent fields in complex terrain, Boundary-Layer Meteorology 83, 43-73, 1997.

[3] Hurley, P., The Air Pollution Model (TAPM) Version 2. User manual, CSIRO Atmospheric Research Internal Paper No. 25, 2002.

[4] Hurley, P., Physick, W. \& Luhar, A., The Air Pollution Model (TAPM) Version 2. Part 2: summary of some verification studies, CSIRO Atmospheric Research Technical Paper No. 57. 2002. 
[5] Azzi M., Johnson G.M. \& Cope M., An introduction to the generic reaction set photochemical smog mechanism, Proceedings of the 11th International Clean Air and Environment Conference, Brisbane, Clean Air Society of Australia \& New Zealand. 1992.

[6] Venkatram A., Karamchandani P., Prasad P., Sloane C., Saxena P. \& Goldstein R., The development of a model to examine source-receptor relationships for visibility on the Colorado Plateau, Journal of the Air and Waste Management Association, 47, 286-301.1997.

[7] EMEP/CORINAIR, Emissions Inventory Guidebook - 3d edition, European Environmental Agency, Technical Report n ${ }^{\circ}$ 30.2002.

[8] Monteiro, A., Borrego, C., Tchepel, O., Santos, P. \& Miranda, A. I, Atmospheric Emissions Inventory - POLAR2, Model Application, 7CNQA, 18-20 Abril, Aveiro, Portugal, pp.954-958.2001.

[9] Instituto de Meteorologia, Caracterização climática 2003. 2004.

[10] Willmott, C.J., On the validation of models, Physical Geography 2, 184 194.1981.

[11] Environmental Protection Agency, Guideline for regulatory application of the Urban Airshed Model, Research Triangle Park, N.C.: Office of Air Quality Planning and Standards; EPA report nos. EPA - 450/4-91-013, 1991.

[12] Barros, N., Borrego, C., Toll, I., Soriano, C., Jimenez, P., Balsasano, J.M., Urban photochemical pollution in the Iberian Peninsula: Lisboa and Barcelona airsheds, Air and Waste Management Association 53, 347359.2003.

[13] Borrego, C., Tchepel, O., Monteiro, A., Barros, N., Miranda, A., Influence of traffic emissions estimation variability on urban air quality modelling. Water, Air and Soil Pollution, Focus, vol. 2 (5-6). Kluwer Publishers, Dordrecht, 487-499.2002.

[14] Monteiro, A., Vauatard, R., Borrego, C. \& Miranda, A. I., Long-term simulations of photo oxidant pollution over Portugal using the CHIMERE model, Atmospheric Environment 39, 3089-3101, 2004. 